\title{
Reflections on the Comparative Study of the Innovation Ability of Professional Degree Graduates in China and America
}

\author{
Wenhong Liu, Zhonghua Liu \\ School of Electronic and Information, Shanghai Dianji University, Shanghai, China
}

Email address:

liuwenhong@sdju.edu.cn(Wenhong Liu)

To cite this article:

Wenhong Liu, Zhonghua Liu. Reflections on the Comparative Study of the Innovation Ability of Professional Degree Graduates in China and America. Education Journal. Vol. 7, No. 4, 2018, pp. 90-94. doi: 10.11648/j.edu.20180704.13

Received: September 30, 2018; Accepted: October 15, 2018; Published: October 18, 2018

\begin{abstract}
Aiming at training on the innovation ability of professional degree graduates in applied technical universities, we consider using empirical research method and comparative research method to explore the basic and important ideas on this topic. Specifically, we chose Shanghai Dianji University and University of California, Berkeley as the research objects. Shanghai Dianji University is one of applied technical universities, while University of California, Berkeley is one of worldrenowned universities. In cultivation the innovation ability of professional degree graduates, University of California, Berkeley has not only made successful general experience, and also has distinct character. First, we will focus our attention on the aspects of common, and then discuss its characteristic. To train professional degree graduates into leaders in future engineering, University of California, Berkeley forms a complete and distinctive style in the training objectives, application for admission, curriculum design and quality assurance. These are very inspiring for the development of professional degree education. Learning its practice and concrete measures is helpful to explore the training way of professional degree graduates innovation ability in Shanghai Dianji University. As result, the innovation ability of professional degree graduates will be improved, the employment satisfaction and social welcome of professional degree graduate will be enhanced and increased. So this reflection and research is very useful and necessary.
\end{abstract}

Keywords: Professional Degree, Innovation Ability, Comparative Study, Similarity, Characteristic

\section{Introduction}

Professional degree graduate students are a form of graduate education that originated in the United States. At the beginning of the 20th century, the United States included professional degree graduate education in the national higher education system. In 1908, Harvard University awarded the first professional degree in the United States - Master of Business Administration (MBA). Since 1991, China has officially enrolled the first professional degree, MBA. In 2009 , it began to enroll all undergraduate graduates to pursue full-time master's degree. After that, the pace of professional graduate education accelerated, and the number of professional degrees increased rapidly. Rapid expansion; by 2015, the number of professional degree categories will reach 40 , the number of professional degree authorization points will be more than 7,200 , and the number of graduate students enrolled in master's degree will be 376,000 [1].

In recent years, the Chinese and foreign education departments have attached great importance to the cultivation of practical and innovative ability of professional degree graduate students. Relevant authorities have formulated relevant policies, and the training units and experts and scholars have carried out extensive and in-depth research from theory to practice on the cultivation of professional graduate students' practical innovation ability from different angles, and have achieved fruitful research results.

The United States is the earliest and largest country in the world to carry out professional degree postgraduate education. It is also the country of origin of innovation and entrepreneurship education, and is the leader of current theoretical research and practice of entrepreneurship education. In July 2013, the US Department of Commerce released the report "Innovation and Entrepreneurship 
University: Focusing on Higher Education Innovation and Entrepreneurship", which was jointly promoted by more than 140 research university presidents in the United States, and its contents mainly include students. Entrepreneurship, teacher entrepreneurship, technology transformation, schoolenterprise cooperation and participation in regional economic development [2]. It can be seen that research universities in the United States are good at using diverse paths to encourage innovative thinking and innovative activities. Chinese scholars have studied the training of graduate students in American universities. Tang Lei from Southeast University studied the professional degree graduate education of the University of California at Berkeley with the aim of cultivating leaders in the future engineering field. It pointed out that the distinctive cultivation characteristics have great enlightenment to the development of China's engineering master degree education [3]. Liu Chuansheng of Beijing Normal University has studied the innovation and entrepreneurship education of Stanford University, the University of California at Berkeley and the Los Angeles campus. He believes that the theory and practice of innovation and entrepreneurship education in American universities is worthy of reference by Chinese universities [2].

In 2013, the Ministry of Education of the People's Republic of China issued the Opinions of the Ministry of Education on Human Resources and Social Security on Promoting the Reform of the Professional Degree Graduate Education Model, and put the reform of the full-time professional degree master's training model on the work schedule, proposing career needs as Oriented, reform goals with a focus on practical capacity development. Therefore, the significance of the cultivation of the practical ability of full-time professional degree masters is further clarified. Xiang Xinghua of South China University of Technology adopted a qualitative research method that is good at finding commonalities in special, and studied the practical ability structure of professional degree graduates. The core of the practical ability of professional degree graduates is the ability of knowledge application innovation [4]. Su Nan of Xi'an University of Electronic Science and Technology discussed measures to strengthen the cultivation of professional degree graduates' innovation ability and social needs, and proposed to add enterprise elective courses in the course teaching to strengthen the role of science and technology competitions in postgraduate practice teaching [5]. Experts and scholars from other colleges and universities in China have also studied and discussed the cultivation of practical innovation ability of professional degree graduates from different perspectives, and have achieved fruitful research results [6-11].

The professional degree is an imported product. It is neither a simple transplant of foreign education forms nor a simple change of the original academic postgraduate education, but a type of postgraduate education with special laws. The formation and growth of professional graduate students' practical innovation ability also has its own characteristics and laws. It is necessary to study the social needs and educational practice in China through research and study, and deepen the understanding of professional degrees and continuously strengthen the law of professional degree education. grasp. Therefore, the comparative study of Chinese and foreign professional degree postgraduate education is one of the development trends in this field. $\mathrm{Hu}$ Jianbo of Guizhou University of Finance and Economics compared the training mode of professional degree graduates in the United States, Britain, Japan and China [12], and Zhuang Yulin of China University of Petroleum developed the professional master's degree education in the United States, Britain, France and Japan. The situation was investigated and compared with the research on training mode, teaching organization form, curriculum setting and school scale [13]. This study will focus on the cultivation of practical and innovative ability of professional degree graduates in China and the United States. Take Shanghai Dianji University, referred as to our school, and the University of California, Berkeley as examples. Through hands-on experience and first-hand information, comparative analysis, explore commonalities, and learn from experience., development characteristics.

This research will help us to learn the advanced experience of the United States in the cultivation of professional degree graduates in practice and innovation, and promote the research of practical and innovative education theory in our country. It will help to explore the cultivation of the professional innovation ability of professional degree graduate students in our school and improve the professional degree graduate students of our school. The level of practice innovation ability training. Therefore, this project has important theoretical and practical significance for the training of professional degree graduates.

\section{The Main Objectives, Methods and Content of the Research}

The goal of a professional degree is to develop high-level, applied-level professionals with solid theoretical foundations and tailored to the specific needs of a particular industry or occupation. Therefore, professional degree education is oriented to professional needs, attaches importance to the combination of theory and practice, and focuses on solving practical problems. The development of today's world is inseparable from innovation, and innovation requires all kinds of talents with innovative capabilities. In general, the ability to innovate refers to the ability to continuously provide new ideas, new theories, new methods, and new inventions with economic, social, and ecological values. The specific high-level professionals trained in professional degrees are mainly those with practical and innovative ability that can closely combine theory with application. Therefore, cultivating the practical innovation ability of professional degree graduate students is the core and key of professional degree graduate education. At present, with the increasing investment of professional degree graduates in the country, 
the demand for excellent professional degree graduates is becoming more and more urgent. It is also one of the main tasks of college education to cultivate the practical innovation ability of professional degree graduate students.

This study is based on Shanghai Dianji University and the University of California, Berkeley, using empirical research methods and comparative research methods. Through the investigation of the practical innovation ability and training of professional degree graduate students of our school and Berkeley, we obtain objective materials, from individual to general, and summarize them. From practice to theory, then theory to practice; from domestic to foreign, and then from abroad to the country. From the students to the instructors inside and outside the school, then back to the students. In the process of specifically guiding professional degree graduates, we intend to observe and understand the initial state of students' innovative ability when entering the school, pay attention to their changes and improvement in innovation ability after entering the postgraduate study stage, fully understand and sort out the innovation ability of domestic professional degree graduate students. Training objectives, current status, training links and methods. Taking advantage of the opportunity of foreign visits, through the scientific research, academic exchanges, and corporate visits with the same group of graduate students, we can understand the cultivation of the professional ability of the graduate degree in the Berkeley School of Engineering and feel the ability to innovate. On the basis of obtaining first-hand information, we will consider the basic characteristics of innovation ability, sort out the performance of innovation ability, and summarize the role of training links in improving innovation ability.

According to the specific research objectives of this study, it is determined to conduct research from the following aspects:

China and the United States have an understanding of the connotation of innovation capabilities and the requirements for the professional innovation ability of professional degree graduate students.

The main links between China and the United States in the cultivation of professional graduate students' ability to practice innovation.

The main methods and main methods for the training of professional degree graduates in China and the United States.

In this study, we mainly analyze and experience the requirements and specific performance of the professional graduates of the School of Electrical Engineering of Shanghai Dianji University and the School of Engineering of the University of California, Berkeley, and analyze the reasons for their similarities and differences. It sorts out the basic links, core links and unique links in the process of cultivating the professional innovation ability of professional degree graduates between China and the United States, and explores the relationship between these links and the basic quality and characteristic ability of professional degree graduates in practice and innovation, and finds commonality and characteristics. Comparing the similarities and differences between the Chinese and American universities in the main aspects of the innovation ability training of professional degree graduates, and looking for advanced experience that can be used for reference. Further study on how to improve the innovation ability of professional degree students at the theoretical level. Applying the research results to the actual cultivation of the innovation ability of professional degree graduate students in our school.

\section{Research Steps and Application of Results}

First of all, it is mainly aimed at domestic universities and companies, students, school tutors and corporate tutors to understand the practical innovation ability of professional degree graduate students and their training. Then, using the favorable conditions of foreign visits, we will understand the practical and innovative ability of professional degree graduates and their training for Berkeley and California companies, students, school tutors and corporate tutors. Further collect relevant policy documents and academic research results of professional degree graduate training, especially foreign materials in English, and focus on the literature related to the cultivation of practical innovation ability. Learn more about the process of cultivating the professional innovation ability of professional degree graduate students and the main methods and methods used in each link. Learn more about the process of UC Berkeley's practice of developing professional graduates' innovative ability and the main methods and methods used at each stage. Field trips to Berkeley's laboratories, cooperative companies, hands-on contact with teachers and students, and their advanced concepts and experience in the development of professional degree graduates. On the basis of practical investigation and theoretical comparative analysis, we will discuss the commonalities and characteristics of our school and the University of California, Berkeley in the training of professional degree graduate students. Combine the preliminary practical effects, write a summary report on the reform plan, and introduce the reform plan in detail to make the reform The program is feasible and has practical guiding significance; actively organizes project team members to participate in teaching and research activities and projects at all levels.

The research results are first used in the cultivation of the practical innovation ability of the postgraduate degree of electrical engineering in our school. After the establishment of the professional degree graduates of other majors in our school, the scope of application will be expanded. The project's project and completion will have significant and important practical benefits. It can improve the social welcome of our professional degree graduates and enhance the employment satisfaction of our professional degree graduates. At the same time, we will strengthen our school's contact with world famous schools and expand our school's awareness. 


\section{Discussion}

As the master of engineering degree is a kind of practiceoriented, or career-oriented degree type, so in the formulation of training objectives, it is inseparable from the requirements of engineering practice and engineer ability requirements. The University of California, Berkeley, aims to cultivate a master's degree in engineering as a future leader in engineering, based on the needs of today's engineering professionals. This kind of orientation, which matches its own characteristics and meets the needs of Engineering practice, is naturally easier to win the favor of applicants and is easier to achieve. This has brought certain enlightenment to the cultivation of full-time Master of Engineering in our country. In the process of formulating the cultivation goal, we should make good use of our own advantages in disciplines and resources, integrate the interdisciplinary and interdepartmental resources, and consider the personnel specifications urgently needed in the field of Engineering practice, and consider the above two points comprehensively. Set up a talent training target that meets its own characteristics and has a certain market demand.

The cultivation of students' practical ability is the key. Full-time Master of Engineering in China adopts the dual tutorial system which combines in-school training with outof-school practice. However, due to the inertia of in-school training and the inadequacy of attaching importance to theory but neglecting practice in school engineering education, the in-school curriculum learning and out-of-school project practice in full-time Master of Engineering professional degree education are separated. This has lost the synergistic advantage that full-time Master of Engineering co-education should have, both on and off campus, and some of the practices at University of California, Berkeley may inspire us. In order to promote the integration of Engineering master's course learning and project practice and achieve the goal of training future engineering leaders, the University of California, Berkeley, has specifically developed and constructed the Engineering Leadership Education Curriculum Model, which combines professional skills, core leadership courses and project practice. Combination, and a large number of case teaching methods, hiring a large number of teachers with rich industry practice experience for teaching guidance, so that students in school to learn each part of the industry can be combined with the reality.

\section{Conclusion}

Based on empirical research methods and comparative research methods, this study considers the cultivation of the innovative ability of professional degree graduate students in Shanghai Dianji University and in the University of California, Berkeley, and explores the commonalities and characteristics in the cultivation of professional graduate students' practical innovation ability. The advanced experience of the University of California, Berkeley, drawing on the considerations and measures in the cultivation of the professional innovation ability of professional degree graduate students, provides valuable reference for the cultivation of the professional innovation ability of professional degree graduate students in Shanghai Dianji University, thus promoting the professional degree of Shanghai Dianji University. The improvement of practice innovation ability enhances the employment satisfaction and social popularity of graduate students.

\section{Acknowledgements}

This work was supported by 2017 Shanghai Dianji University Graduate Education Research and Reform Leading Project. The project title is Comparative Study on the Innovation Ability of Professional Degree Graduates in China and America. And the author would also like to express her deep appreciation to Professor Fai Ma and the University of California, Berkeley.

\section{References}

[1] Huang Baoyin, Tang Jiwei, Hao Yuliang. The Development of Professional Degree Graduate Education in China [J]. China Higher Education, 2017 (2): 18-24.

[2] Liu Chuansheng. Research and Enlightenment of Innovation and Entrepreneurship in California Colleges and Universities__-Taking Stanford University, University of California at Berkeley and Los Angeles as Examples [J]. School Party Building and Ideological Education, 2016, (23): 15-18.

[3] Tang Lei, Wang Ligen. Discussion on the training mode of engineering masters of the University of California at Berkeley [J]. Jiangsu Higher Education, 2015, (04): 89-92.

[4] Xiang Xinghua, Li Qinghong, Liu Jie. Qualitative Research on the Practical Ability Structure of Full-time Professional Degree Masters [J]. Degree and Graduate Education, 2016, (03): 62-68

[5] Su Nan, Zhang Shangwei. A New Probe into the Cultivation of Creative Ability of Full-time Professional Degree Graduates [J]. China Electric Power Education, 2014, (11): 13-14.

[6] Shao Yeqin, Shi Wei. Exploration on the Cultivation of Creative Practice Ability of Graduates Majoring in Information Science [J]. Education and Teaching Forum, 2016, (51): 141-143.

[7] Zhang Deqiang, Zeng Hong, Wang Hongxiang. Discussion on the Training Mode of Innovative Ability of Full-time Professional Degree Graduates in Machines [J]. Journal of Liaoning University of Technology (Social Science Edition), 2016, (04): 96-100.

[8] Li Ang. Innovation mode and mechanism innovation of electrical engineering graduate degree $[\mathrm{J}]$. China Modern Educational Equipment, 2016, (05): 71-74.

[9] Wang Gui, Yu Guoyan, Zhao Juan, Liu Haitao, Wang Yulin. Exploration on the Reform of the Innovative Ability Cultivation of Full-time Professional Degree Graduates [J]. Contemporary Education Theory and Practice, 2015, (08): 41-43. 
[10] Zhu Xi'an. Research on the Cultivation of Professional Master's Practice Innovation Ability [J]. China Electric Power Education, 2014, (36): 51-52.

[11] Zhang Xinhui, Hu Xitong, Ji Fengkun. Exploration on the Mode of Training Innovative Talents for Electrical Engineering Majors [J]. China Electric Power Education, 2014, (03): 11-13.
[12] $\mathrm{Hu}$ Jianbo. Comparison and Enlightenment of the Training Modes of Professional Degrees between China and Foreign Countries [J]. Contemporary Education Forum, 2015, (04): 46-51.

[13] Zhuang Yulin, Tong Zemin, Zhang Rijun. Comparative study on the education model of full-time professional degree graduates between China and foreign countries [J]. Petroleum Education, 2014, (05): 33-36. 